\title{
Interpretasi Geometri Dari Sebuah Determinan
}

\author{
Riska Yeni $^{1}$, Syamsudhuha ${ }^{2}$, M. D. H Gamal ${ }^{3}$ \\ Jurusan Matematika, Fakultas Mipa, Universitas Riau \\ Jl. HR. Soebrantas No. 155 Simpang Baru, Panam, Pekanbaru, 28293 \\ Email : Riska_yeni@rocketmail.com
}

\begin{abstract}
ABSTRAK
Artikel ini membahas arti geometris dari sebuah determinan. Dengan diketahui sebuah jajargenjang yang dibentuk oleh dua buah vektor kolom suatu matriks, nilai determinan suatu matriks berordo $2 \times 2$ dapat diartikan sebagai luas jajargenjang. Dari sebuah balok atau parallelepiped. yang dibentuk oleh vektor-vektor kolom matriks berordo $3 \times 3$ dapat diartikan sebagai determinan sebagai volume balok atau parallelepiped.
\end{abstract}

Kata Kunci: balok, determinan, jajargenjang, matriks, parallelepiped

\begin{abstract}
We discusses the geometric meaning of a determinant. Given a parallelogram formed by two column vectors of a matrix, the value of the determinant of a $2 \times 2$ matrix can be interpreted as the area of the parallelogram. From a beam or a parallelepiped formed by the column vectors of a $3 \times 3$ matrix, the determinant of the matrix can be interpreted as a beam or parallelepiped volume.
\end{abstract}

Keywords: beam, determinant, parallelogram, matrix, parallelepiped

\section{Pendahuluan}

Pada umumnya di beberapa buku Matematika SMA diberikan konsep determinan secara aljabar berupa rumus-rumus atau metode untuk menghitung nilai determinan, sehingga dengan menghitung selisih antara hasil kali elemen-elemen pada diagonal utama dengan hasil kali elemen-elemen pada diagonal sekunder diperoleh nilai determinan matriks berordo $2 \times 2$, dan dengan menggunakan aturan Sarrus diperoleh nilai determinan matriks berordo $3 \times 3[1,3,4,7]$.

Padahal konsep determinan juga dapat dipelajari dengan pendekatan geometri. Sebelumnya, Hefferon [5] telah memperkenalan konsep determinan secara geometri. Namun yang dibahas oleh Hefferon adalah konsep determinan matriks berordo $2 \times 2$ sebagai luas jajargenjang yang penurunan rumusnya menggunakan konsep luas segitiga dan segiempat. Oleh karena itu, pada artikel ini akan dibahas konsep determinan matriks berordo $2 \times 2$ secara geometri sebagai luas jajargenjang yang penurunan rumusnya menggunakan konsep hasilkali silang (Crossproduct).

Pada artikel ini juga dibahas arti geometris dari determinan matriks berordo $3 \times 3$, sehingga diperoleh bahwa determinan matriks berordo $3 \times 3$ sebagai volume balok atau parallelepiped. Lalu, dengan konsep determinan matriks berordo $2 \times 2$ sebagai luas jajargenjang, sifat-sifat fungsi determinan juga dapat dijelaskan secara geometri. Adapun sifat-sifat fungsi determinan yang dibahas pada artikel ini adalah determinan matriks transpose dan sifat determinan bernilai nol.

Demikian, konsep determinan tidak hanya dapat dipelajari menurut satu titik pandang saja, karena determinan juga dapat dipahami melalui pendekatan geometri maupun aljabar itu sendiri. Oleh karena itu, penulis tertarik untuk memperkenalkan konsep determinan matriks secara geometri dan pengembangannya terhadap sifat-sifat fungsi determinan. 


\section{Metode Penelitian}

Misalkan diberikan sebuah jajargenjang yang dibentuk oleh penjumlahan dua vektor kolom di $R^{2}$ yaitu $u=$ $\left[x_{1}, y_{1}\right]^{T}$ dan $v=\left[x_{2}, y_{2}\right]^{T}$, dengan $\operatorname{det}[u, v] \geq 0$. Lalu dengan menentukan tinggi jajargenjang sebagai $\|v\| \sin \theta$, maka luas jajargenjang dapat ditentukan dengan rumus $\|u\|\|v\| \sin \theta$, sehingga berdasarkan Teorema 2 maka diperoleh luas jajargenjang merupakan nilai mutlak dari determinan matriks berordo $2 \times$ 2 , dengan vektor-vektor kolom $u$ dan $v$.

Selanjutnya, diberikan sebuah balok dan parallelepiped yang dibentuk oleh vektor-vektor kolom di $R^{3}$ yaitu $u, v$ dan $w$, dengan $\operatorname{det}[u, v, w] \geq 0$. Dengan menentukan tinggi masing-masing balok atau parallelepiped ini, maka dapat ditentukan volume dari balok dan parallelepiped sebagai hasil kali luas alas dengan tingginya, sehingga diperoleh bahwa volume sebuah balok atau parallelepiped merupakan nilai mutlak dari determinan matriks berordo $3 \times 3$, dengan vektor-vektor kolom $u, v$ dan $w$.

Selanjutnya juga dibahas pengembangan determinan matriks berordo $2 \times 2$ sebagai luas jajargenjang terhadap sifat fungsi determinan matriks transpose dan sifat determinan matriks bernilai nol. Misalkan diberikan jajargenjang $L_{A}$ dan jajargenjang $L_{A^{T}}$ berturut-turut dibentuk oleh penjumlahan dua vektor kolom $u$ dan $v$, dan penjumlahan vektor $r$ dan $s$ di $R^{2}, u=\left[x_{1}, y_{1}\right]^{T}$ dan $v=\left[x_{2}, y_{2}\right]^{T}$, dengan det $[u, v] \geq 0, r=$ $\left[x_{1}, x_{2}\right]^{T}$ dan $r=\left[y_{1}, y_{2}\right]^{T}$, dengan det $[r, s] \geq 0$. Dengan memperhatikan gambar jajargenjang $L_{A}$ dan jajargenjang $L_{A^{T}}$, maka tampak bahwa terjadinya pergeseran (translasi) vektor-vektor pembentuk jajargenjang $L_{A}$ pada gambar jajargenjang $L_{A^{T}}$, namun luas jajargenjang $L_{A}$ dan jajargenjang $L_{A^{T}}$ adalah tetap sama. Lalu, jika diberikan sebuah garis lurus yang dibentuk oleh dua buah vektor kolom di $R^{2}$ yaitu $u=\left[x_{1}, y_{1}\right]^{T}$ dan $v=$ $\left[k x_{1}, k y_{1}\right]^{T}$, maka dengan memperhatikan garis lurus ini diperoleh bahwa tidak terdapatnya ruang antara vektor $u$ dan $v$ sehingga dapat dikatakan luasnya nol.

\section{Hasil dan Pembahasan}

Teorema 1. Jika $u$ dan $v$ adalah vektor-vektor pada $R^{3}$, maka $\|u \times v\|$ adalah sama dengan luas jajargenjang yang dibentuk oleh vektor $u$ dan $v$.

Bukti: Menurut identitas Lagrange,

$$
\|\boldsymbol{u} \times \boldsymbol{v}\|^{2}=\|\boldsymbol{u}\|^{2}\|v\|^{2}-(u \cdot v)^{2}
$$

jika $\theta$ menyatakan sudut antara $u$ dan $v$, maka $u \cdot v=\|u\|\|v\| \cos \theta$, sehingga persamaan (1) dapat ditulis sebagai

$$
\begin{aligned}
\|u \times v\|^{2} & =\|u\|^{2}\|v\|^{2}-\|u\|^{2}\|v\|^{2} \cos ^{2} \theta \\
& =\|u\|^{2}\|v\|^{2}\left(1-\cos ^{2} \theta\right) \\
& =\|u\|^{2}\|v\|^{2} \sin ^{2} \theta
\end{aligned}
$$

jadi,

$$
\|u \times v\|=\|u\|\|v\| \sin \theta
$$

dengan $\|v\| \sin \theta$ merupakan tinggi dari jajargenjang $A$ yang dibentuk oleh vektor $u$ dan $v$ (Gambar 1).

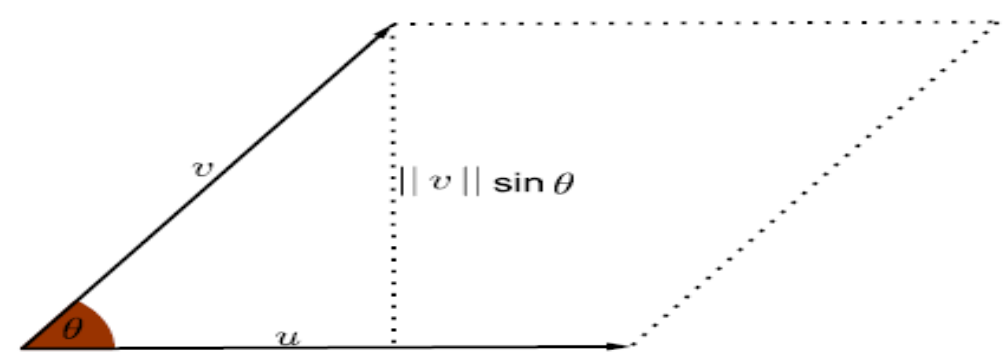

Gambar 1: Jajargenjang $A$ dengan tinggi $\|v\| \sin \theta$ 
Berdasarkan persamaan (2), luas jajargenjang $A$ adalah

$$
\text { luas jajargenjang } \begin{aligned}
A & =\text { alas } \times \text { tinggi } \\
& =\|u\|\|v\| \sin \theta=\|u \times v\|
\end{aligned}
$$

Jadi, terbukti bahwa luas jajargenjang $A=\|u \times v\|$.

Teorema 2. Misalkan diberikan vektor $u=\left(u_{1}, u_{2}\right)$ dan $v=\left(v_{1}, v_{2}\right)$ maka luas jajargenjang di $R^{2}$ yang dibentuk oleh vektor $u$ dan $v$ adalah nilai mutlak dari determinan

$$
\left[\begin{array}{ll}
u_{1} & u_{2} \\
v_{1} & v_{2}
\end{array}\right]
$$

Bukti: Dapat dibuktikan dengan menggunakan Teorema 1. Bagaimanapun Teorema 1 diterapkan untuk di $R^{3}$, sedangkan $u=\left(u_{1}, u_{2}\right)$ dan $v=\left(v_{1}, v_{2}\right)$ merupakan di $R^{2}$. Untuk menyelesaikan masalah dimensi ini, $u$ dan $v$ yang mungkin dipandang sebagai vektor-vektor yang berada pada bidang koordinat XY, padahal merupakan berada pada koordinat XYZ (Gambar 2), dimana $u=\left(u_{1}, u_{2}, 0\right)$ dan $v=\left(v_{1}, v_{2}, 0\right)$, sehingga

$$
u \times v=\left|\begin{array}{ccc}
i & j & k \\
u_{1} & u_{2} & 0 \\
v_{1} & v_{2} & 0
\end{array}\right|=\left|\begin{array}{ll}
u_{1} & u_{2} \\
v_{1} & v_{2}
\end{array}\right| k=\operatorname{det}\left[\begin{array}{ll}
u_{1} & u_{2} \\
v_{1} & v_{2}
\end{array}\right] k .
$$

Berdasarkan Teorema 1 dan jika $\|k\|=1$, maka luas jajargenjang pada Gambar 2 adalah

Luas jajargenjang $=\|u \times v\|=\left\|\operatorname{det}\left[\begin{array}{ll}u_{1} & u_{2} \\ v_{1} & v_{2}\end{array}\right] k\right\|=\left|\operatorname{det}\left[\begin{array}{ll}u_{1} & u_{2} \\ v_{1} & v_{2}\end{array}\right]\|k\|=\right| \operatorname{det}\left[\begin{array}{ll}u_{1} & u_{2} \\ v_{1} & v_{2}\end{array}\right] \mid$.

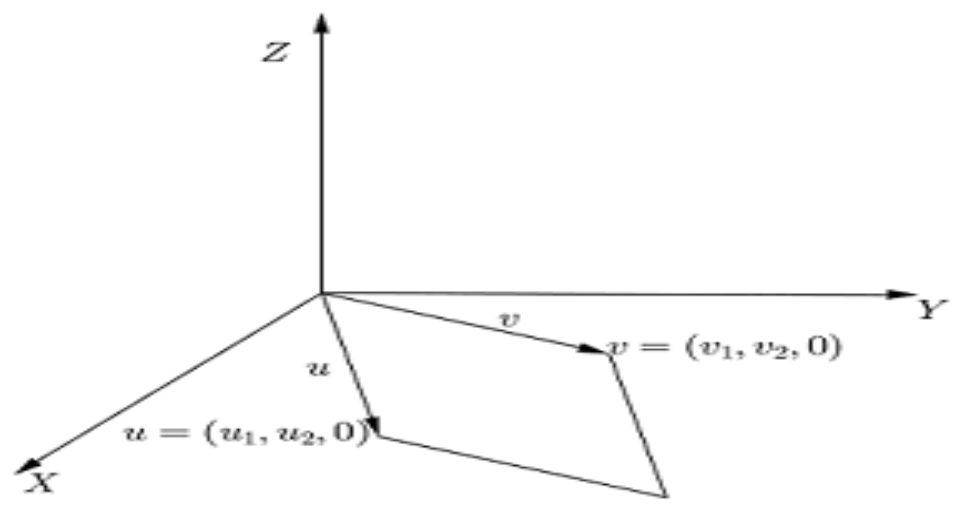

Gambar 2: Jajargenjang yang dibentuk oleh vektor $u$ dan $v$ $R^{2}$ yaitu,

Gambar 3 merupakan sebuah jajargenjang $G$ yang dibentuk oleh penjumlahan dua vektor kolom di

$$
u=\left(\begin{array}{l}
x_{1} \\
y_{1}
\end{array}\right) \text { dan } v=\left(\begin{array}{l}
x_{2} \\
y_{2}
\end{array}\right) \text {, dengan } \operatorname{det}[u, v] \geq 0 .
$$




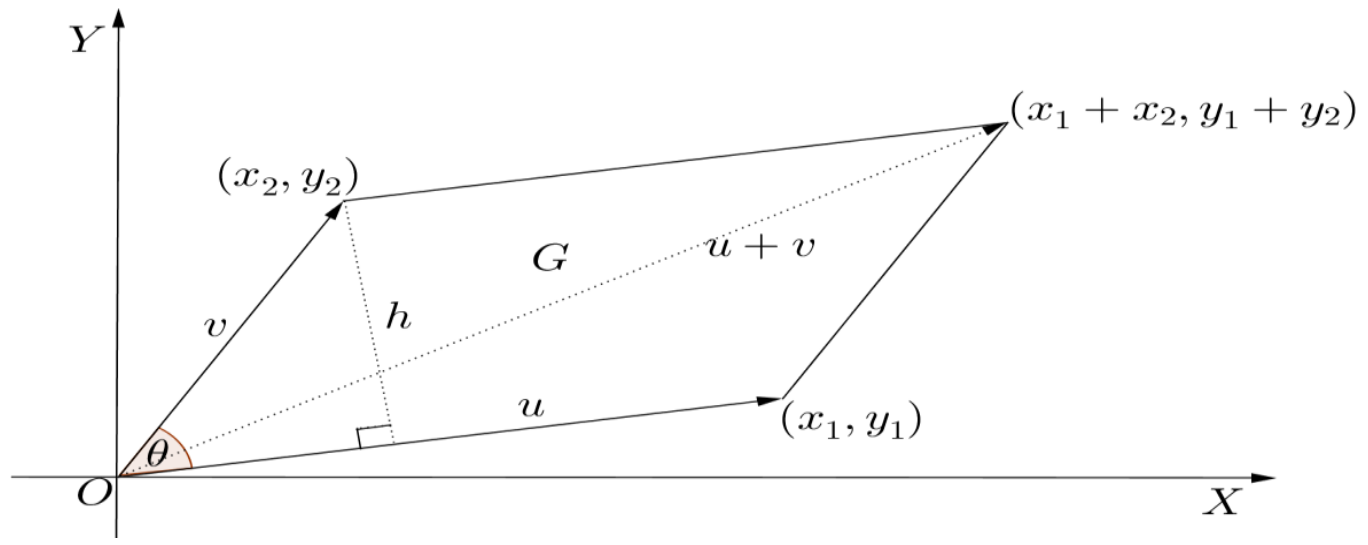

Gambar 3: Jajargenjang $G$ yang dibentuk oleh vektor $u$ dan $v$

Berdasarkan Teorema 2, maka luas jajargenjang $G$ adalah nilai mutlak dari determinan matriks dengan vektor-vektor kolom $u$ dan $v$.

$$
L_{G}=x_{1} y_{2}-x_{2} y_{1}
$$

Pada Gambar 3 juga diketahui bahwa luas jajargenjang $G$ adalah,

$$
\begin{aligned}
L_{G} & =\text { alas } \times \text { tinggi } \\
L_{G} & =\|u\|\|v\| \sin \theta, \text { dengan tinggi } h=\|v\| \sin \theta .
\end{aligned}
$$

Substitusi persamaan (3) ke persamaan (4), sehingga dapat ditunjukkan

$$
\|u\|\|v\| \sin \theta=x_{1} y_{2}-x_{2} y_{1}
$$

Berdasarkan Gambar 3, diperoleh

$$
\begin{gathered}
\|u\|=\sqrt{\left(x_{1}\right)^{2}+\left(y_{1}\right)^{2}} \\
\|v\|=\sqrt{\left(x_{2}\right)^{2}+\left(y_{2}\right)^{2}} \\
u \cdot v=x_{1} x_{2}+y_{1} y_{2} \\
h=\|v\| \sin \theta .
\end{gathered}
$$

Selanjutnya dapat ditentukan tinggi jajargenjang $G$ pada Gambar 3 dengan cara membuat sebuah Segitiga dengan tinggi $h$ seperti tampak pada Gambar 4.

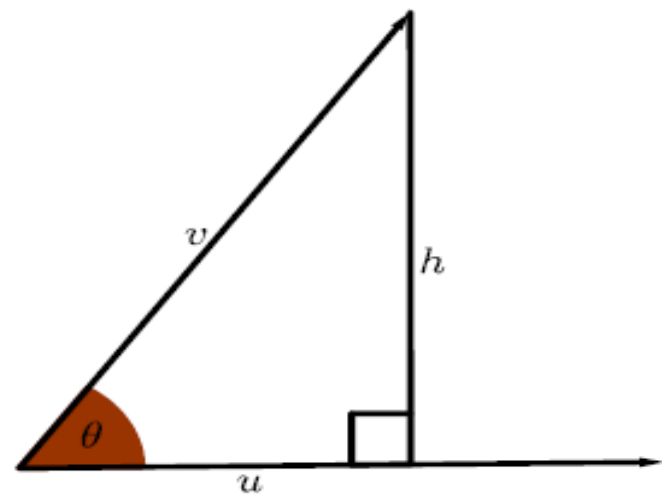

Gambar 4: Segitiga dengan tinggi $h$ 
Dengan menggunakan rumus sudut antara dua vektor pada Gambar 4, maka diperoleh

$$
\cos \theta=\frac{u \cdot v}{\|u\|\|v\|},
$$

sehingga berdasarkan nilai $\cos \theta$ pada persamaan (6), maka dengan menggunakan aturan Phytagoras diperoleh

$$
\sin \theta=\frac{\sqrt{(\|u\|\|v\|)^{2}-(u \cdot v)^{2}}}{\|u\|\|v\|} .
$$

Dengan mensubstitusikan nilai $\sin \theta$ pada persamaan (4) dengan persamaan 7), maka diperoleh $L_{G}=\|u\|\|v\| \sin \theta$

$$
\begin{aligned}
& =\sqrt{(\|u\|\|v\|)^{2}-(u \cdot v)^{2}} \\
& =\sqrt{\left(\left(x_{1}\right)^{2}+\left(y_{1}\right)^{2}\right)\left(\left(x_{2}\right)^{2}+\left(y_{2}\right)^{2}\right)-\left(x_{1} x_{2}+y_{1} y_{2}\right)^{2}} \\
& =\sqrt{\left.\left(x_{1}\right)^{2}\left(x_{2}\right)^{2}+\left(x_{1}\right)^{2}\left(y_{2}\right)^{2}+\left(x_{2}\right)^{2}\left(y_{1}\right)^{2}+\left(y_{1}\right)^{2}\left(y_{2}\right)^{2}\right)-\left\{\left(x_{1}\right)^{2}\left(x_{2}\right)^{2}+2 x_{1} x_{2} y_{1} y_{2}+\left(y_{1}\right)^{2}\left(y_{2}\right)^{2}\right\}} \\
& =\sqrt{\left(x_{1}\right)^{2}\left(y_{2}\right)^{2}+\left(y_{1}\right)^{2}\left(x_{2}\right)^{2}-2 x_{1} x_{2} y_{1} y_{2}} \\
& =\sqrt{\left(x_{1} y_{2}-x_{2} y_{1}\right)^{2}}
\end{aligned}
$$

Luas jajargenjang $G=x_{1} y_{2}-x_{2} y_{1}$.

Luas jajargenjang $G$ ini merupakan nilai determinan dari matriks

$$
G=[u, v]=\left[\begin{array}{ll}
x_{1} & x_{2} \\
y_{1} & y_{2}
\end{array}\right]
$$

yang vektor kolomnya terdiri dari dua titik koordinat jajargenjang. Karena luas tidak mungkin negatif, maka dapat dikatakan bahwa luas suatu jajargenjang adalah

$$
\text { Luas jajargenjang }=|\operatorname{det}[u, v]|
$$

Seperti halnya determinan matriks berordo $2 \times 2$, determinan matriks berordo $3 \times 3$ juga dapat diinterpretasikan secara geometri. Secara geometri, determinan matriks berordo $3 \times 3$ dapat diartikan sebagai volume balok atau parallelepiped [5,6].

Misalkan diberikan sebuah Balok yang dibentuk oleh vektor-vektor kolom $u=\left(a_{11}, 0,0\right)$, $v=\left(0, a_{22}, 0\right)$, dan $w=\left(0,0, a_{33}\right)$ di $R^{3}$, dengan titik-titik sudut balok merupakan elemen-elemen vektor kolom matriks $B$ dan $\operatorname{det}[u, v, w] \geq 0$. (lihat Gambar 5) 


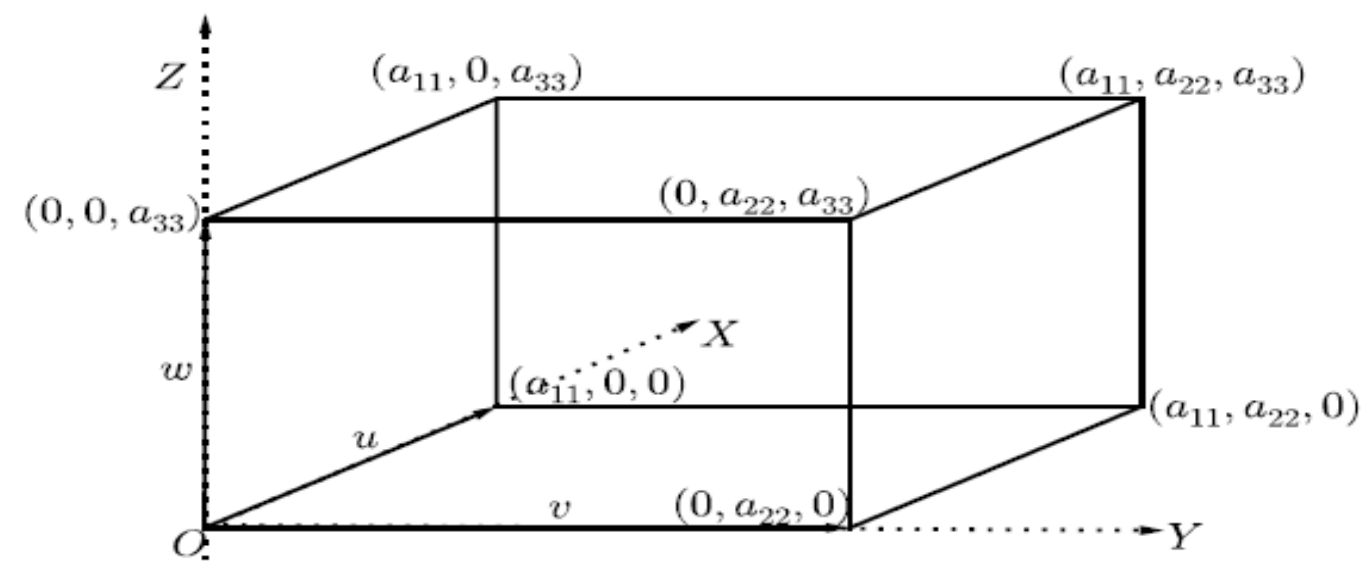

Gambar 5: Balok yang dibentuk oleh vektor-vektor $u, v$, dan $w$

Berdasarkan ilustrasi pada Gambar 5 diperoleh

$$
\begin{gathered}
\text { panjang }=\|u\|=a_{22} \\
\text { lebar }=\|v\|=a_{11} \\
\text { tinggi }=\|w\|=a_{33} .
\end{gathered}
$$

Demikian, volume balok diperoleh dengan rumus

$$
\begin{aligned}
V & =\text { panjang } \times \text { lebar } \times \text { ting } i \\
& =a_{22} \times a_{11} \times a_{33} \\
V & =a_{11} a_{22} a_{33} .
\end{aligned}
$$

Volume balok ini merupakan nilai determinan matriks $B$ yaitu

$$
B=\left[\begin{array}{ccc}
a_{11} & 0 & 0 \\
0 & a_{22} & 0 \\
0 & 0 & a_{33}
\end{array}\right],
$$

yang merupakan matriks segitiga dengan vektor-vektor kolomnya sebagai titik-titik koordinat $(x, y, z)$. Demikian telah ditunjukkan bahwa determinan matriks berordo $3 \times 3$ sebagai volume suatu balok. Karena volume suatu balok tidak mungkin negatif, maka digunakan tanda mutlak determinan matriks berordo $3 \times 3$ sebagai volume balok $B$.

Parallelepiped merupakan sebuah bangun ruang yang dibentuk oleh enam bentuk jajargenjang. Volume dari suatu parallelepiped merupakan hasilkali dari luas alas dan tingginya.

Misalnya diberikan sebuah parallelepiped yang dibentuk oleh vektor-vektor $u$, $v$, dan $w$, dengan $\operatorname{det}[u, v, w]^{T} \geq 0$ dan $u=\left(u_{1}, u_{2}, u_{3}\right), \quad v=\left(v_{1}, v_{2}, v_{3}\right)$, dan $w=\left(w_{1}, w_{2}, w_{3}\right)$ di $R^{3}$. Secara geometri dapat digambarkan sebagai Gambar 6 . 


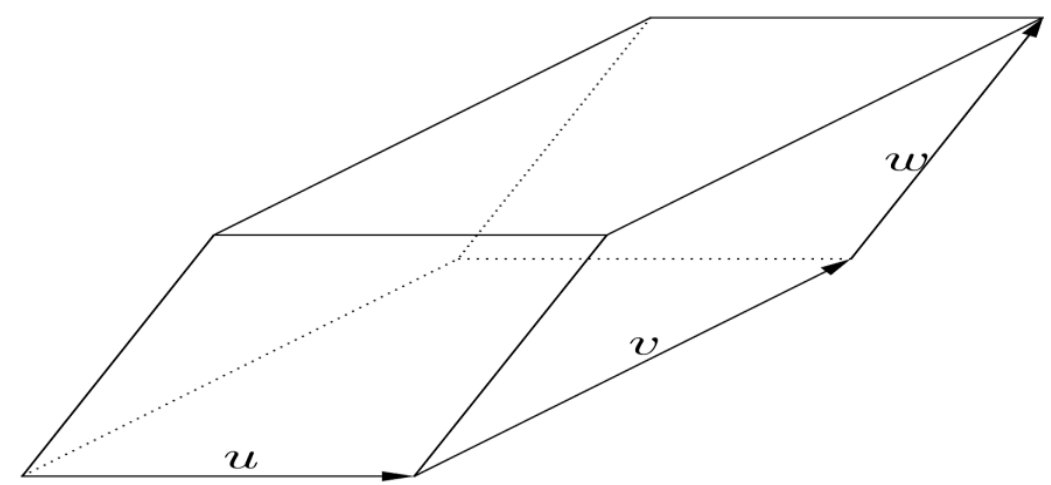

Gambar 6: Parallelepiped yang dibentuk oleh vektor $u, v$, dan $w$

Berdasarkan Gambar 6 diperoleh alas dari parallelepiped berbentuk jajargenjang yang dibentuk oleh vektor $u$ dan $v$, sehingga dengan menggunakan Teorema 1 diperoleh luas alas $=\|v \times u\|$.

Selanjutnya akan ditentukan tinggi parallelepiped dengan cara membuat sebuah garis tegak lurus terhadap alas seperti tampak pada Gambar 7.

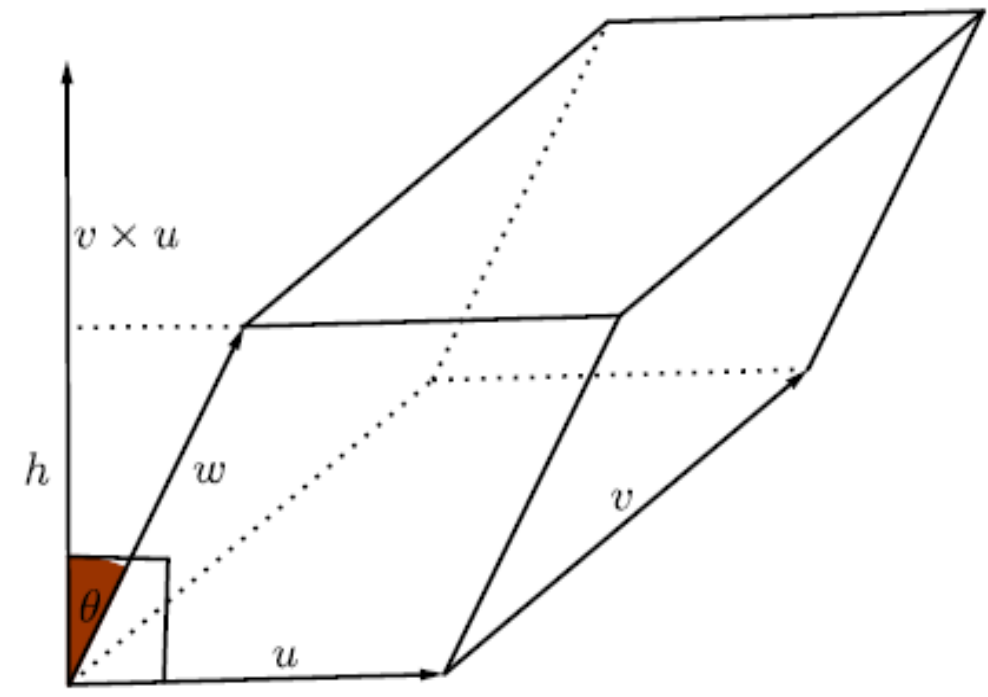

Gambar 7: Parallelepiped dengan tinggi $h$

Sebelum menentukan tinggi parallelepiped, dapat ditentukan nilai kosinus $\theta$ pada Gambar 8

$$
\cos \theta=\frac{h}{\|w\|},
$$

dengan menggunakan rumus sudut antara dua vektor yaitu $v \times u$ dan $w$ maka diperoleh

$$
\cos \theta=\frac{(v \times u) \cdot w}{\|v \times u\| \cdot\|w\|},
$$

substitusi persamaan (8) ke persamaan (9) diperoleh

$$
\frac{h}{\|w\|}=\frac{(v \times u) \cdot w}{\|v \times u\| \cdot\|w\|}
$$




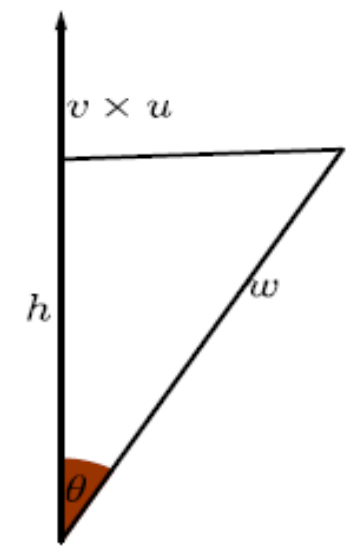

Gambar 8: Sudut antara dua vektor

sehingga diperoleh tinggi parallelepiped $h$ yang merupakan hasil proyeksi $w$ terhadap $v \times u$ yaitu,

$$
h=\frac{(v \times u) \cdot w}{\|v \times u\|} .
$$

Setelah diketahui luas alas dan tinggi parallelepiped, maka dapat ditentukan volume dari parallelepiped yakni

$$
\begin{aligned}
V & =\text { Luas alas } \times \text { tinggi } \\
& =(\|v \times u\|) \times\left(\frac{(v \times u) \cdot w}{\|v \times u\|}\right) \\
& =(v \times u) \cdot w \\
& =w \cdot(v \times u) \\
V & =\operatorname{det}\left[\begin{array}{lll}
w_{1} & w_{2} & w_{3} \\
v_{1} & v_{2} & v_{3} \\
u_{1} & u_{2} & u_{3}
\end{array}\right] .
\end{aligned}
$$

Demikian, determinan matriks berordo $3 \times 3$ dapat dikatakan sebagai volume dari parallelepiped. Karena volume parallelepiped tidak mungkin negatif, maka digunakan nilai mutlak determinan matriks sebagai volume parallelepiped.

$$
\left|\operatorname{det}[u, v, w]^{T}\right|
$$

Selanjutnya akan dibahas pengembangan determinan matriks berordo $2 \times 2$ sebagai luas jajargenjang terhadap sifat determinan matriks transpose dan determinan bernilai nol.

Misal diberikan jajargenjang $L_{A}$ dan jajargenjang $L_{A^{T}}$ seperti tampak pada Gambar 8 .

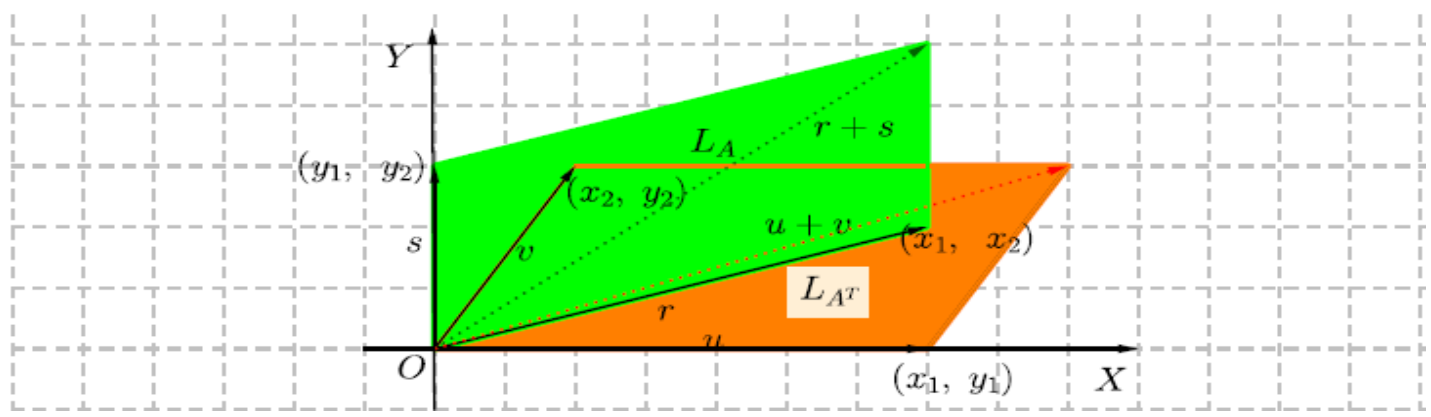

Gambar 8: Hubungan jajargenjang $L_{A}$ dan jajargenjang $\boldsymbol{L}_{\boldsymbol{A}^{T}}$ 